Н. Л. Никулина, Л. М. Аверина. Теоретико-методологический подход к разработке стратегических направлений взаимодействия регионов

УДК 332.1

DOI: $10.18101 / 2304-4446-2019-4-57-66$

\title{
ТЕОРЕТИКО-МЕТОДОЛОГИЧЕСКИЙ ПОДХОД К РАЗРАБОТКЕ СТРАТЕГИЧЕСКИХ НАПРАВЛЕНИЙ ВЗАИМОДЕЙСТВИЯ РЕГИОНОВ
}

\author{
(C) Никулина Наталья Леонидовна \\ кандидат экономических наук, старший научный сотрудник \\ E-mail: nikulinanl@mail.ru
}

\author{
(C) Аверина Лидия Михайловна \\ младший научный сотрудник \\ E-mail: laverina@mail.ru
}

Институт экономики УрО РАН

Россия, 620014, г. Екатеринбург, ул. Московская, 29

В статье представлен теоретико-методологический подход к разработке стратегических направлений межрегионального взаимодействия регионов Урала и сопредельных северных, приполярных и арктических территорий в экономической сфере, в основу которого положен учет, с одной стороны, ресурсных возможностей территорий нового хозяйственного освоения и их потребности в готовой промышленной продукции, с другой стороны - значительного экономического и инновационного потенциала индустриально развитых уральских регионов в сочетании с их возрастающей потребностью в сырьевых и энергетических ресурсах. В ходе исследования выявлено, что деятельность уральских предприятий и научных организаций по разработке новых технологий и созданию оборудования, приборов, программного обеспечения для решения экологических проблем Арктики в соответствии с принципом «умной специализации» может быть той нишей, которая позволит предприятиям Урала выйти на новые технологические рынки сбыта продукции, в том числе мировые.

Ключевые слова: пространственное развитие; стратегические направления; межрегиональное взаимодействие; регионы Урала; северные, приполярные и арктические территории; экологические проблемы; антропогенная нагрузка; «умная специализация»; уральские предприятия и научные организации; проекты экологической направленности.

\section{Для цитирования}

Никулина Н. Л., Аверина Л. М. Теоретико-методологический подход к разработке стратегических направлений взаимодействия регионов // Вестник Бурятского государственного университета. Экономика и менеджмент. 2019. № 4. С. 57-66.

В современных условиях в России все большее внимание уделяется межрегиональному взаимодействию. С точки зрения совершенствования пространственной организации экономики страны роль межрегионального взаимодействия заключается в формировании единого экономического пространства страны за счет роста его плотности, связанности и целостности путем интеграции дифференцированных по своему потенциалу и уровню развития территориально локализованных хозяйственных систем (регионов) [1]. Значение межрегионального сотрудничества в современных условиях заключается во взаимовыгодном укреплении хозяйственных связей субъектов РФ, объединении экономических потенциа- 
лов регионов для решения наиболее масштабных инвестиционных проектов, оптимизации размещения на их территории инфраструктурных объектов [2], распространении технологий и инноваций, диффузии знаний и информации.

Общие принципы формирования согласованных основ взаимодействия составных частей (субъектов) Российской Федерации по решению задач социально-экономического развития государства установлены Конституцией РФ (статьи $8,74)$, цели, задачи, приоритеты конкретизируются в разработанных в этой области стратегических документах федерального и регионального уровня. В настоящее время основным стратегическим документом пространственного развития страны является Стратегия пространственного развития РФ до 2025 года, в которой обозначен общий вектор межрегионального взаимодействия - усиление межрегионального сотрудничества и координации социально-экономического развития субъектов Российской Федерации в рамках макрорегионов. В свою очередь, активизация межрегионального сотрудничества обусловила необходимость применения новых теоретико-методологических подходов к исследованию сущности пространственной организации экономики страны, в т. ч. нового подхода к решению задачи усиления межрегионального взаимодействия.

Межрегиональное партнерство имеет значительную теоретическую базу. Вопросам исследования сущности, форм, преимуществ и эффектов межтерриториального взаимодействия и сотрудничества территорий и экономических субъектов уделяется значительное внимание со стороны ученых, начиная с теорий абсолютных (А. Смита) и относительных (Д. Рикардо) преимуществ [3; 4] и до настоящего времени. Теоретические аспекты межрегионального взаимодействия получили свое развитие в рамках теорий размещения, пространственного развития, сравнительных преимуществ, кластерных и других теорий, а также разного вида концепций, разработанных в рамках данных теорий. В современной научной литературе, как западной, так и отечественной, рассматриваются различные направления межрегионального взаимодействия. Так, значительное количество публикаций посвящено выявлению взаимосвязей уровней межрегионального взаимодействия и инновационной активности регионов $[5 ; 6]$. Результатом исследований является вывод о том, что при прочих равных условиях наличие устойчивых межрегиональных связей способствует повышению уровня инновационной активности в регионах.

Еще одно направление исследований - рассмотрение межрегионального взаимодействия в контексте территориального развития. В современной экономической науке широкое признание получила теория поляризованного развития Ф. Перру, развитая далее в трудах Ж. Будвиля, П. Потье и др. В то же время, по мнению ряда российских ученых [7], концепция поляризованного развития «опорных регионов», используемая во многих странах в рамках теории поляризованного развития, для современной России на данном этапе ее развития не является оптимальным вариантом пространственного развития страны, поскольку она в экономических условиях России 2000-х гг. усиливает поляризацию пространственного развития, и, соответственно, приводит к повышению межрегиональной дифференциации в уровнях благосостояния населения субъектов Российской Федерации. Нивелирование обозначенных негативных тенденций в пространственном развитии страны требует разработки новых подходов к простран- 
Н. Л. Никулина, Л. М. Аверина. Теоретико-методологический подход к разработке стратегических направлений взаимодействия регионов

ственному развитию, основанных в т. ч. на поступательном переходе от конкуренции регионов к их кооперационному взаимодействию.

В современных геостратегических и геоэкономических условиях для России особое значение имеет оценка потенциальных возможностей межрегиональной интеграции индустриально развитых регионов с полярными северными и арктическими территориями - территориями нового хозяйственного освоения. Системное освоение данных территорий - актуальная проблема, связанная с геополитическими, экономическими, экологическими, военно-стратегическими интересами России в этом регионе.

Вопросам межрегионального взаимодействия индустриально развитых регионов с северными, полярными и арктическими территориями посвящено значительно количество публикаций в научных изданиях. В работах Института экономики УрО РАН [8-10] обобщены результаты исследований по теоретическим аспектам межрегионального взаимодействия, основным направлениям, формам, механизмам и методам межрегионального сотрудничества индустриальных регионов Урала с Ямало-Ненецким и Ханты-Мансийским автономными округами. Определено, что специфика межрегионального взаимодействия данных регионов обусловлена специфичностью имеющихся ресурсов, различиями в экономическом потенциале, структуре экономики, уровне социально-экономического развития, что обусловливает их возможности и ограничения в осуществлении межрегионального взаимодействия.

Экономические интересы России в освоении Арктики связаны с наличием на данной территории крупных запасов природных ресурсов, в т. ч. углеводородов, освоение которых обеспечивает рост национальной экономики и сохранение ведущих позиций России на мировом рынке углеводородов как в настоящее время, так и на перспективу. Исходя из этого, ряд исследований Института экономики УрО РАН посвящен вопросам оценки промышленного взаимодействия уральских регионов с территориями Тюменского Севера [9, с. 152-193; 11]. Данный подход основан на учете, с одной стороны, ресурсных возможностей территорий нового хозяйственного освоения и их потребности в готовой промышленной продукции, с другой стороны - значительном экономическом потенциале индустриально-развитых уральских регионов в сочетании с их возрастающей потребностью в сырьевых и энергетических ресурсах. Среди факторов, способствующих межрегиональной промышленной интеграции, отмечается географическая близость, сложившиеся транспортно-экономические кооперационные связи (предприятия и организации Среднего Урала традиционно являются поставщиками и разработчиками техники, технологий и оборудования для многих северных производственных проектов, от нефте-, газодобычи до транспортировки углеводородов), высокий производственно-технологический, научный, инновационный, транспортный потенциал Урала.

Ряд исследований направлен на определение маркетинговых контуров промышленного взаимодействия Арктики и Среднего Урала [10, с. 17; 12]. Данный подход основан на использовании имеющихся и перспективных компетенций уральских товаропроизводителей в соответствии с потребностями предприятий и организаций, дислоцированных на территории Тюменского Севера. Эффективность данного взаимодействия для уральских предприятий основана на укрепле- 
нии позиций на приоритетных для них рынках отдельных секторов базовых отраслей (нефтегазовое и транспортное машиностроение, трубное производство), выходе на новые технологические рынки (лазерные, аддитивные, IT-технологии и др.), возможности встраивания в межрегиональные и глобальные производственные цепочки.

Новые перспективы для всех участников промышленной межрегиональной интеграции связаны с реализацией арктических проектов развития инфраструктуры: развитие Северного морского пути, строительство железной дороги Бованенково - морской порт Сабетта, железнодорожной линии «Обская - Салехард - Надым - Коротчаево» (проект Северный широтный ход).

Развитие арктической транспортно-логистической инфраструктуры, осуществляемое при активном участии уральских предприятий с использованием новейших научно-технологических разработок и современных логистических технологий, создает новые логистические траектории для предприятий Уральского макрорегиона при продвижении их продукции на рынки Северной и Западной Европы, Юго-Восточной Азии через Северный морской путь. Реализация логистического потенциала порта Сабетта позволит осуществлять экспорт и импорт продукции по кратчайшему и экономически выгодному пути. Одной из новых логистических траекторий продвижения продукции уральских предприятий на мировые рынки является индустриально-логистическая схема (Уральская Арктика - Урал - Казахстан - Китай и в перспективе Индия).

Более подробно перспективы и эффективность межрегиональной интеграции Урала и сопредельных северных и арктических территории в вопросах развития транспортно-логистической инфраструктуры нами рассмотрены в исследовании «Реализация экспортного потенциала региона на основе формирования транспортно-логистического кластера» [13].

Итогом исследований, выполненных авторами в 2014-2018 гг., является вывод о роли межрегиональной промышленной и транспортно-инфраструктурной интеграции в обеспечении взаимодополняемости экономик сопредельных регионов, рационализации пространственных связей в новых рыночных схемах производственно-технологической кооперации предприятий и регионов.

Одним из важнейших направлений межрегионального промышленного взаимодействия является инновационная деятельность, которая также отражена в исследованиях Института экономики УрО РАН [9, с. 152-193; 11]: рассмотрены действующие и предложены новые механизмы, методы, формы, сотрудничества регионов в инновационной сфере, дана оценка предполагаемых двухсторонних эффектов. Однако современные реалии в социально-экономическом положении России, развитие экономической науки актуализируют поиск новых подходов к оценке инновационной составляющей в межрегиональном сотрудничестве. В последующих исследованиях предполагается развить теоретикометодологические подходы к разработке данного направления.

Интеграция промышленно развитых территорий УрФО с северными регионами не ограничивается экономической и транспортно-инфраструктурной составляющей, а носит комплексный системный характер. Она касается не только освоения природных ресурсов Севера, их использования на емких и стабильных сырьевых и топливных рынках Урала, но и сферы технологий сохранения приро- 
Н. Л. Никулина, Л. М. Аверина. Теоретико-методологический подход к разработке стратегических направлений взаимодействия регионов

ды Севера, охраны окружающей среды, применения экологически безопасных технологий, повышения качества жизни населения [9, с. 152-193].

Освоение Арктики сопряжено с усилением антропогенной нагрузки на хрупкую арктическую экосистему. Накопленный за многие годы экологический ущерб также способствует ухудшению экологической ситуации в Арктической зоне. Как отмечает Ю. И. Соколов, природа Арктики не в состоянии переработать накопленные отходы даже за сотни лет [14].

К числу основных экологических проблем Арктической зоны РФ относятся: неблагополучное состояние окружающей среды (загрязнение атмосферного воздуха, водных объектов, почв, деградация биотических компонентов и экосистем); рост объемов отходов производства и потребления; нарастание негативного воздействия изменений климата, в т. ч. опасных гидрометеорологических явлений; недостаточная эффективность мониторинга последствий природных и техногенных катастроф; отсутствие рынка экологических услуг; истощение дешевых запасов качественных углеводородов, а также ряда других стратегических важных природных ресурсов (фосфоритов, редкоземельных металлов и др.); низкий уровень извлечения сырья при разработке месторождений углеводородов; значительная доля устаревших, экологически грязных производств низкого уровня передела.

О. Е. Медведева выделяет три категории экологического ущерба. Настоящий, или текущий, экологический ущерб - это ущерб, вызванный нарушением природоохранных норм в процессе хозяйственной деятельности, либо ущерб, вызванный аварийной ситуацией. Прошлый экологический ущерб, или, как теперь принято его называть, накопленный вред, представляет собой экологический ущерб, причиненный прошлой деятельностью людей и предприятий. Будущий ущерб, или проектный ущерб, рассчитывается и оценивается на стадии разработки проекта [15].

Главными принципами освоения Арктики, по мнению В. Н. Чарушина, являются принципы:

- превентивности (раннее предупреждение негативных экологических тенденций или их минимизация);

- экологического императива (первостепенность экологических целей по отношению к экономическим);

- эколого-экономической сбалансированности (размещение и развитие материального производства на территории в соответствии с ее экологической техноемкостью);

- гуманизации (учет интересов коренного населения Севера);

- биотической регуляции окружающей среды (сохранение ландшафтного и биологического разнообразия) [16].

В Стратегии национальной безопасности Российской Федерации Россия рассматривается как лидер при освоении ресурсов Мирового океана и Арктики, но освоение Арктики не должно приводить к ухудшению экологической ситуации в месте работы. В этой связи следует отметить, что предприятия Урала обладают необходимыми компетенциями для производства оборудования, машин и материалов, востребованных для работы в условиях Крайнего Севера, в т. ч. для реализации проектов экологической направленности для снижения антропогенной 
нагрузки в Арктической зоне РФ. Номенклатура продукции уральских предприятий представлена в подготовленном в 2018 г. Минпромторгом России каталоге высокотехнологичной промышленной продукции и услуг для нужд Арктической зоны Российской Федерации с учетом различных климатических зон на данной территории и предъявляемых условий эксплуатации.

Значительное количество разработок в области современных способов эффективного обращения с отходами, а также в сфере мониторинга и прогнозирования изменения климата и его последствий в Арктической зоне представлено академической, вузовской, отраслевой наукой Урала, часть которых приведена в таблице.

Таблица

Проекты (научные разработки) предприятий и организаций Свердловской области, направленные на снижение антропогенной нагрузки и прогнозирование влияния изменения климата в Арктической зоне $Р \Phi^{1}[10$, с. 17]

\begin{tabular}{|c|c|}
\hline Название организации & Описание проекта (научной разработки) \\
\hline $\begin{array}{l}\text { АО НПО Автоматики им. акаде- } \\
\text { мика Н. А. Семихатова }\end{array}$ & $\begin{array}{l}\text { Разработка и производство программно-аппаратных комплек- } \\
\text { сов, исследовательского и контрольно-измерительного обору- } \\
\text { дования, различных систем мониторинга и сопутствующего } \\
\text { программного обеспечения. Эффективность обусловлена высо- } \\
\text { кой степенью востребованности в условиях острого недостатка } \\
\text { информации об устойчивости эксплуатационных характеристик } \\
\text { машин и оборудования в условиях низких температур, а также } \\
\text { слабой изученности последствий различных сценариев техно- } \\
\text { генного и климатического влияния на экосистему северных } \\
\text { территорий }\end{array}$ \\
\hline \multirow[t]{2}{*}{$\begin{array}{l}\text { Уральский федеральный уни- } \\
\text { верситет им. Первого президен- } \\
\text { та России Б. Н. Ельцина }\end{array}$} & $\begin{array}{l}\text { Разработки в сфере IТ-технологий, предназначенные для: мо- } \\
\text { ниторинга акваторий повышенной опасности и поисково- } \\
\text { спасательных операций в условиях Арктики; } \\
\text { комплексного моделирования и прогнозирования последствий } \\
\text { долгосрочной эксплуатации добывающих скважин и различных } \\
\text { технических систем, применяемых на северных нефтегазовых } \\
\text { месторождениях }\end{array}$ \\
\hline & $\begin{array}{l}\text { Разработки, предназначенные для прогнозирования влияния } \\
\text { изменения климата и режима осадков на скорость таяния веч- } \\
\text { ной мерзлоты }\end{array}$ \\
\hline $\begin{array}{l}\text { Уральский научно- } \\
\text { исследовательских химический } \\
\text { институт (УНИХИМ) }\end{array}$ & $\begin{array}{l}\text { Разработка современных способов эффективного обращения с } \\
\text { отходами }\end{array}$ \\
\hline
\end{tabular}

Значительный практический интерес представляет разработанная уральскими учеными высокотехнологичная система очистки бурового раствора и утилизации продуктов бурения на основе принципа «нулевого сброса», применение которой направлено на соответствие требованиям экологической безопасности при освоении Арктического шельфа РФ.

Реализация проектов уральских предприятий и научных организаций по разработке новых технологий и созданию оборудования, приборов, программного

\footnotetext{
${ }^{1}$ Материалы Правительства Свердловской области.
} 
Н. Л. Никулина, Л. М. Аверина. Теоретико-методологический подход к разработке стратегических направлений взаимодействия регионов

обеспечения для решения экологических проблем Арктики позволит в значительной степени достичь результатов, определенных в Долгосрочном прогнозе научно-технологического развития Российской Федерации на период до 2030 года:

- снижение уровня негативного воздействия хозяйственной деятельности (образования отходов производства и потребления, выбросов загрязняющих веществ в атмосферный воздух, сбросов в водные объекты) на природную среду и здоровье населения; разработка и применение экологически эффективных технологий мирового уровня в основных отраслях экономики;

- создание системы мониторинга, оценки и прогнозирования состояния окружающей среды, чрезвычайных ситуаций природного и техногенного характера, изменений климата, необходимой для последующего внедрения современных технологий снижения уровня негативного воздействия на экономику и здоровье населения;

- разработка высокоэффективных безопасных технологий морской разведки и добычи углеводородов в экстремальных природно-климатических условиях, включая способы предупреждения и ликвидации аварийных разливов нефти; технологий разведки и добычи твердых полезных ископаемых на прибрежном и глубоководном шельфе;

- создание соответствующего оборудования и материалов, необходимого программного обеспечения.

Деятельность уральских предприятий и научных организаций по разработке новых технологий и созданию оборудования, приборов, программного обеспечения для решения экологических проблем Арктики может быть для них той нишей, которая, в соответствии с принципом «умной специализации», позволит предприятиям Урала выйти на новые технологические рынки сбыта продукции, в т. ч. мировые, а разработка и/или адаптация современных технологий, высокотехнологичного оборудования, технических средств могут быть востребованы также в смежных отраслях экономики России и других стран.

Таким образом, экологическое направление в системе межрегионального взаимодействия Урала и сопредельных территорий Тюменского Севера будет способствовать не только снижению антропогенной нагрузки в Арктике, но и росту выпуска новых видов высокотехнологичной продукции на предприятиях Урала, росту инновационного потенциала регионов.

На наш взгляд, требуют отдельных разработок и могут быть темой дальнейших исследований задача взаимодействия регионов в области создания и развития телекоммуникационной инфраструктуры Арктики, поскольку освоение северных территорий невозможно без единого информационного пространства, а также вопросы широкого использования в освоении Арктики цифровых технологий.

Дальнейшие исследования авторов предполагают разработку инструментальных методов организации межрегионального взаимодействия субъектов РФ на основе экономико-математического моделирования.

В ходе исследования получены следующие выводы:

1. Развитие межрегиональной экономической и транспортноинфраструктурной интеграции обеспечивает: 
- получение двусторонних экономических эффектов на базе взаимодополняемости экономик сопредельных регионов;

- диверсификацию экономики взаимодействующих регионов за счет развития инновационной составляющей как на Урале, так и в северных регионах;

- рационализацию пространственных связей в рыночных схемах производственно-технологической кооперации предприятий и регионов.

2. Укрепление экономического сотрудничества регионов выступает важным фактором развития каждого из них.

Для уральских регионов рост промышленного производства с расширением рынков сбыта продукции способствует повышению экономической активности хозяйствующих субъектов на их территории и, как следствие, региональному экономическому росту. Уральские предприятия получают дополнительный стимул для развития инновационных производств с выходом на новые рынки высокотехнологичной продукции, а также дополнительные возможности для реализации их экспортного потенциала через формируемые арктические международные транспортные коридоры.

Для северных регионов важнейшим экономическим эффектом межрегионального взаимодействия является создание предпосылок для перехода экономики региона на новый технологический уклад, возможность решения ряда экологических проблем и задач в системе жизнеобеспечения на основе внедрения высоких технологий.

Таким образом, межрегиональное взаимодействие регионов Урала и сопредельных северных, приполярных и арктических территорий в экономической сфере может стать важнейшим условием их дальнейшего экономического роста.

\section{Благодарность}

Статья подготовлена в соответствии с Планом НИР для Лаборатории моделирования пространственного развития территорий ФГБУН Института экономики УрО РАН на 2019 год.

\section{Литература}

1. Мирзоев Р. С. Межрегиональные взаимодействия в российском экономическом пространстве [Электронный ресурс] // Вестн. Волгогр. гос. ун-та. Сер. 3. Экон. Экол. 2011. № 1(18). URL: https://volsu.ru/upload/medialibrary/b08/5_fnmdhiilpghjvu.pdf (дата обращения: 25.05.2019).

2. Николаев М. А., Махотаева М. Ю. Методологические аспекты межрегионального взаимодействия субъектов Российской Федерации [Электронный ресурс] // Научнотехнические ведомости Санкт-Петербургского государственного политехнического университета. Экономические науки. 2012. URL: https://cyberleninka.ru/article/n/ metodologicheskie-aspekty-mezhregionalnogo-vzaimodeystviya-subektov-rossiyskoy-federatsii (дата обращения: 27.06.2019).

3. Смит А. Исследование о природе и причинах богатства народов // Антология экономической классики: в 2 т. / предисл. И. А. Столярова. М., 1993. Т. 1. 475 с.

4. Рикардо Д. Принципы политической экономии и налогового обложения // Антология экономической классики: в 2 т. / предисл. И. А. Столярова. М., 1993. Т. 1. 475 с.

5. Fritsch M., Lukas R. Innovation, cooperation, and the region // Innovation, Industry Evolution and Employment / eds. D. B. Audretsch, R. Thurik. Cambridge: Cambridge University Press, 1999. P. 157-181. 
Н. Л. Никулина, Л. М. Аверина. Теоретико-методологический подход к разработке стратегических направлений взаимодействия регионов

6. Fritsch M. Does R\&D-cooperation behavior differ between regions? // Industry and Innovation. 2003. Vol. 10(1). P. 25-39.

7. Дубровская Ю. Инструменты и институты активизации межрегионального взаимодействия в отечественной экономике [Электронный ресурс] // Вестник Омского университета. Cер. Экономика. 2017. URL: https://cyberleninka.ru/article/n/instrumenty-iinstituty-aktivizatsii-mezhregionalnogo-vzaimodeystviya-v-otechestvennoy-ekonomike (дата обращения: 27.06.2019).

8. Пространственная парадигма освоения малоизученных территорий: опт, проблемы, решения / под ред. А. И. Татаркина. Екатеринбург: Институт экономики УрО РАН, 2009. $460 \mathrm{c}$

9. Разработка стратегических ориентиров развития и институтов освоения северных, полярных и арктических территорий / под ред. А. И. Татаркина. Екатеринбург: Институт экономики УрО РАН, 2014. 508 с.

10. Сценарные подходы к реализации уральского вектора освоения и развития российской Арктики / отв. ред. Ю. Г. Лаврикова ; Институт экономики УрО РАН. Екатеринбург: Изд-во АМБ, 2017. 340 с.

11. Макарова И. В., Аверина Л. М., Захарова Л. А. Основные направления формирования стратегии импортозамещения при реализации уральского вектора освоения и развития Арктики // Региональная экономика: теория и практика. 2016. № 12. С. 191-202.

12. Коровин Г. Б., Аверина Л. М., Захарова Л. А. Опережающее импортозамещение для реализации арктических проектов // Вестник УрФУ. Сер.: Экономика и управление. 2018. T. 17, № 6. С. 970-985.

13. Реализация экспортного потенциала региона на основе формирования транспортно-логистического кластера: монография / Ю. Г. Лаврикова [и др.]. Екатеринбург: Институт экономики УрО РАН, 2017. 170 с.

14. Соколов Ю. И. Арктика: к проблеме накопленного экологического ущерба // Арктика: экология и экономика. 2013. № 2(10). С. 18-27.

15. Медведева О. Е. Задачи оценки экологического ущерба в Арктической зоне // Арктика и Север. 2015. № 18. С. 131-147.

16. Понизовкина Е. Российская Арктика: системный взгляд [Электронный ресурс]. URL: http://www.uran.ru/node/3956 (дата обращения: 20.05.2019).

\section{THEORETICAL AND METHODOLOGICAL APPROACH TO THE DEVELOPMENT OF STRATEGIC DIRECTIONS FOR REGIONAL INTERACTION}

Natalya L. Nikulina

Cand. Sci. (Econ.), Senior Researcher,

Institute of Economics, Ural Branch of RAS

29 Moskovskaya St., Ekaterinburg 620014, Russia

E-mail: nikulinanl@mail.ru

Lidia M. Averina

Junior Researcher,

Institute of Economics, Ural Branch of RAS

29 Moskovskaya St., Ekaterinburg 620014, Russia

E-mail: laverina@mail.ru

The article presents a theoretical and methodological approach to the development of strategic directions for economic interaction between the regions of Ural and adjacent northern, polar and arctic territories, which considers, on the one hand, the resource capabilities of the new territories for development and their demand for finished industrial products, on the 
other hand, the significant economic and innovative potential of the industrially developed Ural regions and their increasing demand for raw materials and energy resources. We have revealed that the activities of Ural enterprises and scientific organizations aimed at development of new technologies and equipment, devices and software for solving the environmental problems of the Arctic in accordance with the principle of "smart specialization" may be a niche that will allow Ural enterprises to enter new technological market outlets, including worldwide market.

Keywords: spatial development; strategic directions; regional interaction; regions of Ural; northern, polar and arctic territories; environmental problems; anthropogenic load; "smart specialization"; Ural enterprises and scientific organizations; environmental projects. 